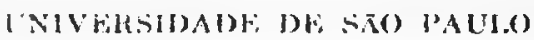

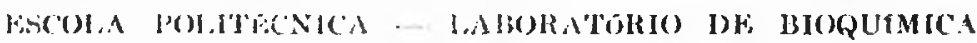

Diretor: l'rof. Irr. Renalo, Fonsec'i Riheirn

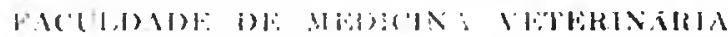

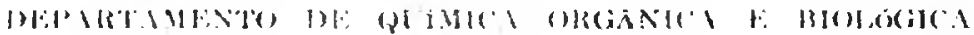

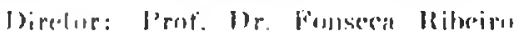

\title{
DETERMINAÇÃO DO CÁLCIO, FŌSFORO, FERRO E CINZAS EM ALGUMAS HORTALIÇAS DA FAMILIA COMPOSITAE LINN
}

\author{
ALFACE. Lactuca satiza, L.: ALMEIRÃO. Chicorium intybus. I.: \\ ESCAROLA, Lachuca scuriola. I.: CHICOREA. Chicorium pndiva. L.

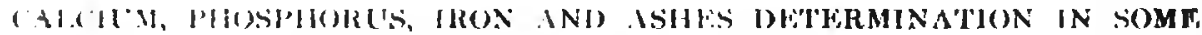

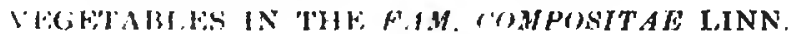

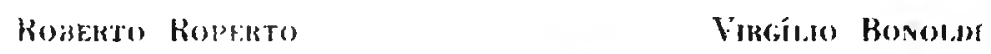

Isab.tina Prestes Monzoni

Prosseguindo en nosso trahalho de deteminaçāo do cálcio, fósforo e ferro. cunjuntamente com o corteúdo mineral total. em hortaliças cultivadas em noisso meio. apresentamos com o presente trabalho os teôres encontrarlos em algumas es. pécies pertencentes à família Compositae. Como é dado ver. salvo para o den. te-de-leão (Taraxacum sp). cuja utilização : muito restritâ em nossas mesas. lodos os representantes de reconhecido interêsse para a nutrição e pertencentes a essa família foram examinados no particular da finalidade que objetivamos no trabalho que vimos realizando. Realmente, um destaque ou preferência por qualquer das hortaliças dessa família m torantr às anas qualidades sápida- e de mesa. serí sempre de ordem jessoal.

\section{MATERIAI, F, METOODOS}

Tal qual em trabalho anterior. sôbre as Cruciferae, as determinações efe. tuaram-se sôbre a parte comestivel pròpriamente dita da folha e em estado na. tural. afastados os caules e partes fibrosas. cuidando-se. na tomada de amostra 
de seguir o critério culinário que preside a utiljzaçăo do vegetal, para fins alimentares humanos.

$\mathrm{O}_{\text {s }}$ nétodos empregados são os mesmos do trabalho anterior (Roptraro. Bo.

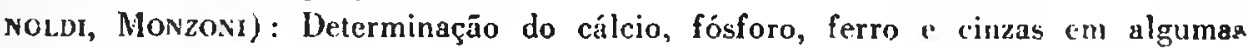
hortaliças da família das Cruciferae: -- Couve verde (Brassica oleracca, I. var. acephala, D.C.); couve tronchuda (Brassica oleracea, L. var. bullata, D.C.) : repolho (Brassica oleracea, L. var. capitata, L.); 'agriāo d'água (Roripa nasiur. sium, Rusby), Rev. Fac. Med. Vet.. S. Paulo, 4(4): 523. 1952.

\section{COMEINTRRIOS}

Mais do que outra finalidade, presentemente só nos move o intuito de apresentar os dados obtidos através de dosagens efetuadas sôlore a parte pròpria. mente comestivel e com os métodos seguros e accessiveis; a descrição dos quai se apresentou para a conveniência dos interessados em tais assuntos. Itm exame crítico e comparativo uão só com o auxílio dos dados encontrados na literatura. como entre as diversas famílias, o faremos posteriormente, terminadas as de. terminaçúes em andamento e que estamos efeluando a propósito de outras hor. taliças das familias Chenopodiaceae, Umbelliferae e Cucurbitaceae. Entretanto, cabe, ante os dados da presente publicação, notar que, além dos teôres infe. riores de cálcio e fósforo en relação à família das Cruciferae, a relação entre êsses elementos nesta família é sensivelmente pouco favorável, havendo mesmo, como é dado ver, para a Escarola, relação inferior à unidade. se hem que pró. xima dela $(0,95)$. Além disso, nenhuma das horlaliças da familia sob exame. apresenta a relação preconizada pela maioria dos nutrólogos, como a que deva ser satisfcita, para contrabalançar as necessidades metabólicas gerais do organismo, ou seja 3:1. Este fato, poderia ser demérito, se o considerássemos iso. ladamente. Nenhuma dieta equilibrada, porém, conterá tais hortaliças como alimentos de base. Nas dietas em que estas hortaliças figurem em quantidades altas haverá conveniência em corrigir com outros alimentos a relação cálcio-fósforo. Deve ser considerado também que não hasta satisfazer o equilibrio cálcio-fósforo na composição dos alimentos: - - e necessário ter-se em linha de conta o coeficiente de assimilaçāo dos diversos alimentos que entram na com. posição de cada cardápio. Assinn, por exemplo, além do teôr de ferro encontrado numa determinada hortaliça, o que importará sohremodo é o coeficiente de aproveitamento, a assimilabilidade do ferro existente, e que é, segundo dados correntes na literatura, cêrca de $6.3 \%$ para o almerão e alface, e cêrca de $72 \%$ para a chicórea. Este último número também cabe à couve, o teôr de ferro por nós obtido tendo sido objeto da publicação anterior a propósito das Brassicaceae. Bem poucas hortaliças, entretanto, apresentam o apanágio de uma assimilação 100\%: Fintre elas, e para citar uma, temos a couve-flôr. 
Voltaremos, aliás, a êste ponto, ao tempo em que de posse dos dados obtidos em determinaçōes processadas em membros de outras famílias, pudermos fazer uma resenha geral e termos em vista de conjunto sôbre tão interessante assunto.

\section{K E S L L M}

(). autores determinaram os teôres de ferro, cálcio e fósforo, além das einzas, sôbre a parte comestivel e no estado crú, de algumas hortaliças da famí lia das Compositue. Encontraram como média das dezesseis determinaçóes efetuadas em exemplares de cultivo local, para êsses elementos, respectivamente. os guintes números (mg para $100 \mathrm{~g}$ da amostra):

\begin{tabular}{|c|c|c|c|}
\hline & Fe & Cid & $r$ \\
\hline Fiscarolit (Lactuca scariolt, l..) & $: 3,0$ & 33,6 & $3+, 6$ \\
\hline ('hicórea (chicorium endivic, I.) .. & 6,2 & 35,3 & 16,6 \\
\hline Alfare (Larfurat valiea, J..) & 2,7 & 18,4 & 32,2 \\
\hline Almeirão ('hicorium intylıus. 1.) & 7,9 & $\pi 3,2$ & $3 \overline{0}, 3$ \\
\hline
\end{tabular}

As relaçōes cálcio.fósforo são as seguintes: -... F.scarola (Lactuca scariola, L.) $0,95: 1$; Chicórea (Chicorium endivia, L.) 2,1:1; Alface (Lactuca sativa, L.) 1,5:1; Almeirão (Chicorium intybus. L.) 2,1:1. 


\begin{tabular}{|c|c|c|c|c|c|c|c|c|c|c|c|c|c|c|c|c|}
\hline & \multicolumn{4}{|c|}{ CINZAS (mg/100 g) } & \multicolumn{4}{|c|}{ FERIRO $(\mathrm{mg} / 100 \mathrm{~g})$} & \multicolumn{4}{|c|}{ CALCIO (mg/10n gr) } & \multicolumn{4}{|c|}{ Fosforo (mgidon g) } \\
\hline & 苞 & 苞 & 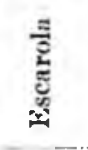 & 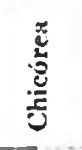 & 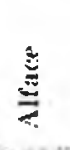 & 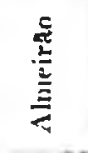 & 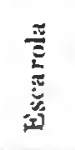 & 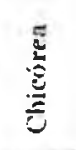 & 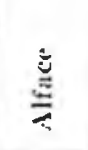 & 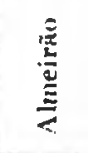 & 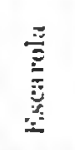 & 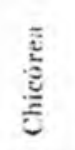 & 气̆ & 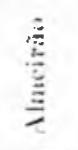 & 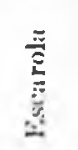 & لِّ \\
\hline 1 & 5.4 & 1518 & $5 \div 29$ & 1432 & 4,0 & $41, \pi$ & 1,3 & 6,2 & 30,2 & $4: 2,1$ & 65,1 & K K & $2-i, i$ & $15, \mathrm{k}$ & $(i 1, k$ & 1.4.t. \\
\hline 2 & 692 & $126 \pi$ & 633 & 1757 & 1,9 & 18,1 & 1,3 & & 9,9 & 85,4 & $25, \pi, i$ & 29,4 & $18 \div 2$ & $=1,1$ & 15,1 & 2,9 \\
\hline 3 & 55.1 & 1287 & 979 & 81.5 & 6,1 & $2: 2,3$ & 1,9 & I,I & 84,2 & 20,5 & 49,2 & 21,9 & 31,3 & $\because 3,9$ & $3: 3,1$ & 17,8 \\
\hline 4 & $i+4$ & 2035 & 1115 & 886 & 1,3 & 1,6 & 3,4 & 5,0 & 119,3 & 105,3 & $15, \mathrm{ti}$ & $2: 3: 2$ & $3 \pi, 5$ & $52, i$ & $2 \pi, 4$ & $1+, 0$ \\
\hline 5 & 585 & 1773 & 755 & 902 & 2,1 & 2,9 & 1.3 & $\pi, 8$ & 19,4 & 127.3 & 27,6 & $: 36,0)$ & 28,4 & $1.3,2$ & $3 \pi, 6$ & 14,9 \\
\hline ; & 585 & 1551 & 789 & 708 & 1,4 & 4,1 & 1,1 & 3,3 & $5+, 5$ & $s \tau, \boldsymbol{H}$ & 35,6 & 15,4 & $9 ., 3,3$ & 36,3 & $1 \geq, 1$ & 14,6 \\
\hline 7 & 482 & $15 \sigma_{2}$ & 65.4 & 811 & 2,1 & 3,6 & 1,9 & $\mathbb{H}, \mathbf{H}$ & 46,7 & 92.3 & 31,4 & 23,4 & צ':31, & 13.6 & 38,5 & 12,8 \\
\hline 8 & $\tau \tau 2$ & 1147 & 735 & 975 & $2, !$ & 4,8 & 1,9 & 11,4 & $3 \pi, 4$ & 53,5 & $8:+, 0$ & 833,3 & ב.: & 25,7 & 38,6 & 5,7 \\
\hline 9 & 818 & 1313 & 629 & $98: 3$ & 2,0 & 3,6 & 1,2 & 1,6 & $5 \cdot 2,7$ & 69,4 & $2-3.3$ & $73,1$. & .81 .5 & $1 !, 7$ & 10,6 & 6,8 \\
\hline 10 & 887 & $11.4 \pi$ & 678 & דิ & 2,1 & 2,1 & :5,3 & 6.7 & 65,1 & $43 . \pi$ & 10,3 & 21,7 & 18.4 & $3 n .5$ & 38,9 & $1 ., 0$ \\
\hline 11 & 529 & $11 \% 5$ & S1.t & 74.4 & 1,3 & 3,6 &,+ 0 & 2,2 & 66,1 & $1,3,2$ & $2.5,6 i$ & $2,2,3)$ & 61,1 & $\because 9,1$ & $80, \pi$ & 15,0 \\
\hline 12 & 633 & 1226 & 1023 & 703 & 1,3 & 3,7 & 5.7 & $1, \gamma$ & 25,7 & 33,1 & 37,3 & 22,0 & 15,1 & $1 \pi, 4$ & i & 14,0 \\
\hline is & 534 & 1211 & $7 \div 0$ & $\tau 29$ & 1,8 & 3,0 & 3,1 & $\because \pi$ & 33,6 & 72,5 & 18,9 & $23,3, i$ & 38,6 & 81.9 & 382,5 & 11,2 \\
\hline 14 & $58 \%$ & 1138 & 1191 & $98 \pi$ & 3.5 & 2,3 & 0,5 & 3,6 & $+\pi, 1$ & 602,45 & 75,0 & 59,4 & $2 ?: 3$ & $11, \hat{i}$ & (19,9 & 24,4 \\
\hline 15 & 382 & 1352 & 768 & 962 & 2,0 & 3,0 & 3,4 & 3,1 & 18,8 & $t i, t$ & 206,3 & $\{0 ; 3$ & 24,4 & $: 33.1$ & $34, i$ & $29, \pi$ \\
\hline 16 & 607 & 1080 & 902 & 813 & 4,5 & 2,6 & 1,7 & 3,8 & 33,3 & 1333,3 & 333,6 & $10: 2$ & 31,3 & $\therefore(1,1$ & 31,4 & 23,6 \\
\hline y & $6: 21$ & 1360 & 807 & 9.49 & $2, \hat{i}$ & $i, 9$ & 3,0 & (i.2. & 18,1 & $i 3,2$ & 33,6 & $: 35.3$ & $3: 2,2$ & 35.3 & 34,6 & 16,6 \\
\hline$\sigma$ & $12 \pi$ & 256 & 180 & 269 & 1.3 & 10.1 & 2.1 & 5,9 & 25,9 & 36,3 & 16,6 & 16.1 & $11, \hat{\pi}$ & 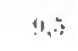 & 111,5 & $!, \pi$ \\
\hline 1 & 20,5 & 18,9 & 22,3 & 28,3 & $+8,1$ & 131,6 & $\pi 0,0$ & 95,2 & 54,5 & H.6 & 49.4 & 51,3 & 36,3 & $\because(6.4)$ & $: 30,3$ & 58,4 \\
\hline
\end{tabular}

